\title{
TOURISM DEVELOPMENT IN VIETNAM: NEW STRATEGY FOR A SUSTAINABLE PATHWAY
}

\author{
Le Thanh TUNG" \\ Ho Chi Minh City Open University, Faculty of Economics and Public Management, \\ 97 Vo Van Tan Street, Ward 6, District 3, Ho Chi Minh City, Vietnam, e-mail: tung.lt@ou.edu.vn
}

\begin{abstract}
Citation: Tung, L.T. (2020). TOURISM DEVELOPMENT IN VIETNAM: NEW STRATEGY FOR A SUSTAINABLE PATHWAY. GeoJournal of Tourism and Geosites, 31(3), 1174-1179. https://doi.org/10.30892/gtg.31332-555
\end{abstract}

\begin{abstract}
Vietnam has been recognized as an emerging tourism market in recent years. Tourism has brought tremendous benefits reflected through socio-economic indicators in this country. Besides, there are many business opportunities coming from the booming of the Vietnamese tourism market. However, the tourism sector is recently facing some huge challenges to maintain sustainable development in the coming time. In this context, a new development strategy is needed to change Vietnam's tourism forward to a sustainable approach. The SWOT analysis is used to show several key aspects presenting strengths, weaknesses, opportunities, threats of Vietnam's tourism industry. Based on the analysis result, some policy implications are provided to develop the Vietnamese tourism sector forward a sustainable pathway in the future.
\end{abstract}

Key words: tourism, tourism policy, sustainable development, development strategy, policymaker, SWOT

$* * * * * *$

\section{INTRODUCTION}

Tourism has an important role in economic development in many countries worldwide. Located in the Asia-Pacific region, which has recorded the highest growth in the number of tourists in recent years (UNWTO, 2020), Vietnam has some advantage conditions need for the booming tourism industry. The first is the long history of culture, Vietnam has a long development history over four thousand years with many dynasties. The second is social diversity, this country has a population of nearly one hundred million people in many ethnic communities including many rich and diverse cultural heritage in many different locations. The third is good geography, the climate in Vietnam is a typical tropical one and basically extended with a long coastline having many beautiful beaches and natural islands. The fourth is the globalization, the Vietnamese tourism has some well-known natural tangibles, intangible cultural heritages and heritage sites listed by well-known international organizations (eg. UNESCO). This country also enforced the conservation of its culture by establishing a national list with thousands of domestic heritage sites (VNAT, 2020). Furthermore, Vietnam has a diverse cuisine culture which includes many delicious foods ranked at the top of the Asian tourism field. Finally, the Vietnamese political regime is very stable, the economy is fastgrowing, society is safe as well as the friendliness of the people. In the context of strong international volatility in recent years, Vietnam continues to be evaluated as a promising dynamic economy and a potential business environment in Asia (Barker and Üngör, 2019).

In such a favorable context, in recent years, Vietnam's tourism industry has developed by leaps and bounds and always been in a group of countries with the fastest growth worldwide (Tung, 2019a). In 2018, the tourism competitiveness of Vietnam has been improving with new records by the $26^{\text {th }}$ position in international tourist arrivals $\left(15.5\right.$ million) and $35^{\text {th }}$ in tourism receipts (US $\$ 10.9$ billion) (UNWTO, 2020). The tourism industry of Vietnam was considered as an emerging tourism market as well as a fast-growing example in the Asia-Pacific region. Tourism has really become a key economic sector of Vietnam when the direct contribution rate of the tourism sector reached eight percent of GDP in 2017 (World Bank, 2019). Besides, tourism has a significant effect on reducing poverty for vulnerable people (Truong, 2018). From the achieved results, the policymakers are striving to construct development strategies for the tourism industry in order to help Vietnam become an attractive and prestigious destination in the tourism world.

However, there is a trade-off, the high growth of tourism has been maintained by the destruction of the natural environment for the fast construction of the resort and hospitality system (Bednárová et al., 2018; Strydom et al., 2019). There are social problems such as the rapid urbanization of tourism cities, deforest, destroy the natural landscapes, an increase in income inequality, or the raise of some criminals. Furthermore, although the speed of tourism growth is quite high, the quality of the development process may have problems. Besides, there are some challenges for the long-term growth of tourism in Vietnam such as the weaknesses in marketing and promotion activity, low-skills of employees, poor infrastructure, or the overload of the transportation systems (World Bank, 2019). So policymakers need to discuss to further promote the sustainable development of the tourism sector. The challenges are raising and require some specific and strong solutions for the Vietnamese tourism industry to really speed-up based on three main strategic directions including improving competitiveness, robust growth and sustainable development. Therefore, policymakers need to have a new approach to the development strategy in the coming years. A new development strategy can help the Vietnamese tourism industry increase faster and sustainably in the future.

This paper has three main contributions to tourism development literature. First, our paper collects and provides the newest database of the tourism of Vietnam, an emerging tourism market in the Asia-Pacific region. Based on this database, the statistics will be deeply analyzed to have an overview of tourism development in Vietnam. Second, our paper establishes a SWOT (Strengths, Weaknesses, Opportunities, and Threats) matrix applied to the tourism of Vietnam. Third, based on the qualitative analysis results, the paper also has some implications for the Vietnamese policymakers in the future. The experience of Vietnam is also a good reference source for other countries to build a sustainable growth tourism industry in the future. The purpose of this paper is presented as follows, (1) provide a historical analysis of tourism development in Vietnam in 2000-2019, (2) Analyzed the strengths, weaknesses, opportunities and threats of Vietnam's tourism industry, (3) recommend some policy implications to enhance the Vietnamese tourism forward a sustainable development path in future.

\section{TOURISM DEVELOPMENT IN VIETNAM: A CURRENT PERSPECTIVE}

The growth trend of the number of tourists

From the beginning of the Doi Moi economic reforms since thirty years ago, the Vietnamese leaders have considered tourism to be a key

\footnotetext{
* Corresponding author
} 
service sector in the long-term economic development strategy (Jansen-Verbeke and Go, 1995, Truong, 2012). Besides having a fast economic growth rate (Tung, 2019b), Vietnam has been recognized as an emerging tourism market in recent years (Hampton et al., 2018). The tourism industry in Vietnam is gradually becoming more proactive in implementing some tasks which support its tourism development policy such as marketing strategy focusing on destination communications, improve tourism infrastructure, increase quality tourism products, ensure security, fostering human resources, inter-regional transport infrastructure, promoting tourism investment and implementing responsible tourism (Thirumaran et al., 2014; Hampton et al., 2018).

Table 1. The number of tourists in Vietnam (Source: General Statistics Office of Vietnam, 2019)

\begin{tabular}{|c|c|c|c|c|c|c|}
\hline \multirow{2}{*}{ Year } & \multicolumn{2}{|c|}{ Domestic tourist } & \multicolumn{2}{|c|}{ Foreign tourist } & \multicolumn{2}{|c|}{ Total number of tourist } \\
\hline & Number (million) & Growth (\%) & Number (million) & Growth (\%) & Number (million) & Growth $(\%)$ \\
\hline 2000 & 11.2 & & 2.1 & & 13.3 & \\
\hline 2001 & 11.7 & 4.5 & 2.3 & 9.5 & 14.0 & 5.3 \\
\hline 2002 & 13.0 & 11.1 & 2.6 & 13.0 & 15.6 & 11.4 \\
\hline 2003 & 13.5 & 3.8 & 2.4 & -7.7 & 15.9 & 1.9 \\
\hline 2004 & 14.5 & 7.4 & 2.9 & 20.8 & 17.4 & 9.4 \\
\hline 2005 & 16.1 & 11.0 & 3.4 & 17.2 & 19.5 & 12.1 \\
\hline 2006 & 17.5 & 8.7 & 3.5 & 2.9 & 21.0 & 7.7 \\
\hline 2007 & 19.2 & 9.7 & 4.2 & 20.0 & 23.4 & 11.4 \\
\hline 2008 & 20.5 & 6.8 & 4.2 & 0.0 & 24.7 & 5.6 \\
\hline 2009 & 25.0 & 22.0 & 3.7 & -11.9 & 28.7 & 16.2 \\
\hline 2010 & 28.0 & 12.0 & 5.0 & 35.1 & 33.0 & 15.0 \\
\hline 2011 & 30.0 & 7.1 & 6.0 & 20.0 & 36.0 & 9.1 \\
\hline 2012 & 32.5 & 8.3 & 6.8 & 13.3 & 39.3 & 9.2 \\
\hline 2013 & 35.0 & 7.7 & 7.5 & 10.3 & 42.5 & 8.1 \\
\hline 2014 & 38.5 & 10.0 & 7.8 & 4.0 & 46.3 & 8.9 \\
\hline 2015 & 57.0 & 48.1 & 7.9 & 1.3 & 64.9 & 40.2 \\
\hline 2016 & 62.0 & 8.8 & 10.0 & 26.6 & 72.0 & 10.9 \\
\hline 2017 & 73.0 & 17.7 & 12.9 & 29.0 & 85.9 & 19.3 \\
\hline 2018 & 80.0 & 9.6 & 15.6 & 20.9 & 95.6 & 11.3 \\
\hline 2019 & 85.0 & 6.3 & 18.0 & 15.4 & 103.0 & 7.7 \\
\hline
\end{tabular}

Tourism is supported strongly by the government because this service sector provides many job opportunities for people, thus producing income for society and became an important financial source of the national budget. So Vietnam's government is attempting to synchronously implement many solutions to put tourism into a leading service sector of the economy. After many multi-dimensional efforts, in 2019, the Vietnamese tourism industry was ranked 63/140 countries worldwide and had an increase at seventeen steps compared to 2011 (WEF, 2019). Besides, Vietnam has been continuously put in the list of ten most-improved countries (UNWTO, 2019). Based on internal strengths, the tourism sector has developed strongly over the past two decades and has an important role in socio-economic developing strategy in Vietnam. According to the statistics of the General Statistics Office of Vietnam, there has been a fast-growing trend of tourists in Vietnam for 2000-2019. For the past twenty years, both foreign tourists and domestic tourists have increased by a double-digit rate (see Table 1) and brought tremendous benefits in improving the socio-economic indicators of Vietnam. The statistics have clearly demonstrated a strong increase in the number of foreign and domestic tourists over time and have been particularly prone to a sharp rise over the past ten years. Besides, the growth expands in the number of both domestic and foreign tourists. In the detail, in the past twenty years, Vietnam has totally welcomed 812 million tourists including 683.2 million domestic arrivals (account by 84.1\%) and 128.8 million foreign arrivals (account by $15.9 \%$ ). Particularly, the increasing speed was higher and higher, which could be proved by the number of visitors in the period 2010-2019 (at 618.5 million people) was higher 3.2 times than the number of visitors in the previous ten years from 2000-2009 (at 193.2 million people). In the previous twenty years, the annual average growth rate of tourists in Vietnam is $10.7 \%$ per year, however, the annual growth rate of foreign arrivals was $11.3 \%$ per year and higher than the domestic arrivals (by $10.6 \%$ per year) in the same periods.

Table 2. Comparative analysis of the growth of tourists in Vietnam, 2000-2019 (Source: General Statistics Office of Vietnam, 2019)

\begin{tabular}{|c|c|c|c|c|c|c|}
\hline \multirow{2}{*}{ Period } & \multicolumn{2}{|c|}{ Domestic tourist } & \multicolumn{2}{c|}{ Foreign tourist } & \multicolumn{2}{c|}{ Total tourist } \\
\cline { 2 - 7 } & Number (Million) & Growth (\%) & Number (Million) & Growth (\%) & Number (Million) & Growth (\%) \\
\hline $2000-2009$ & 162.2 & 8.3 & 31.3 & 5.8 & 193.5 & 7.9 \\
\hline $2010-2019$ & 521.0 & 11.7 & 97.5 & 13.6 & 618.5 \\
\hline $2000-2019$ & 683.2 & 10.6 & 128.8 & 11.3 & 812.0 & 12.0 \\
\hline
\end{tabular}

The number of foreign visitors and domestic visitors also has reached a new record in Vietnam. In detail, the foreign tourist s crossed 18.01 million people and the number of domestic arrivals met 85 million (VNAT, 2020) in 2019. Furthermore, the number of foreign tourists in 2019 was 8.5 times higher than the number in 2000, while the domestic arrivals this year were 7.5 times higher than the volume in 2000 (Figure 1). Some robust solutions have been developed in Vietnam since 2015 so there were breaking points in the trend of tourists. The Vietnamese leaders have been deciding to prioritize tourism as a strategic sector and driver of socio-economic development in the future (World Bank, 2019). Obviously, the Vietnamese tourism industry had a successful breaking point in attracting the number of tourists in 2015 . The statistics also indicate a robust growth trend of tourists in the future.

The current statistics also point out that Vietnam's tourism industry has grown faster than the government's expectations. The achievements of Vietnam's tourism industry is very unbelievable in the past five years when they reached the finish line about eleven years earlier than the national targets. Tourism development is also a good opportunity to strongly promote Vietnam's image to the international community. The fast growth in the number of foreign tourists helps to show the attractiveness of Vietnam's tourism increasingly spread on the world tourism map and the quality of Vietnam's brand destinations also increasingly asserted. Many tourism promotion programs and exchange activities between Vietnam and other tourism markets worldwide also highly contribute to improving images of the Vietnamese tourism industry. The historical analysis results show that the tourism industry affirmed its role and position as a major service sector in Vietnam in the future. However, due to a huge increase in tourists, tourism has been causing negative outcomes 
for the sustainable development path of Vietnam such as damages to the natural environment, deforms the landscapes, fast urbanization, overload in infrastructure, the cultural degradation. Besides, booming waste and pollution of the living environment are gradually becoming risks for the sustainable development of the Vietnamese tourism industry in the future.

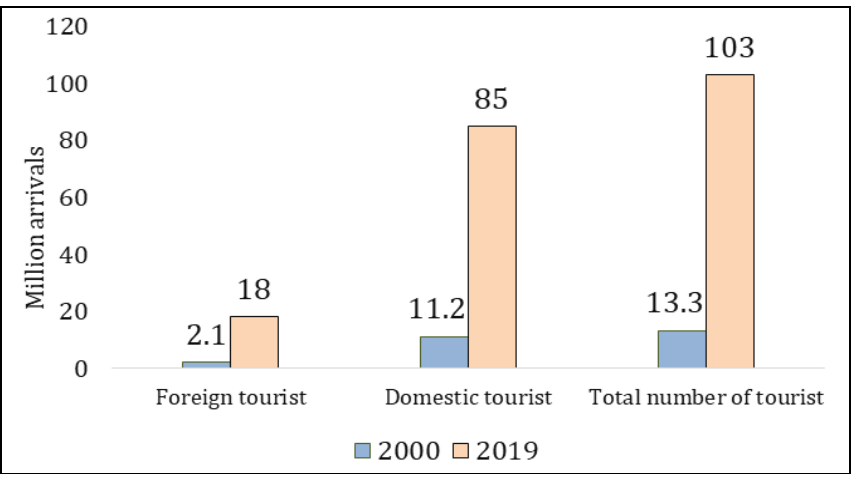

Figure 1. Comparative analysis between 2000 and 2019 (Source: General Statistics Office of Vietnam, 2019)

\section{The demand of foreign tourists}

Although tourism growth is quite high, there is an unbalance in foreign market share in Vietnam. The increase of income per capita helps expand the domestic tourism demand, the growth of Vietnam's tourism industry mainly depended on international tourists from neighboring countries such as China, South Korea, Japan and other markets including the US, Russia, Australia, and Western Europe. In 2019, the two largest markets for Vietnam's tourism are China and South Korea, calculated as 55 percent of the foreign visitors. Besides, Asia still accounted for the highest market share with nearly eighty percent of the total number of foreign visitors to Vietnam (VNAT, 2020).

Based on the statistics, it can be said that tourists from Asia are very important for tourism development in Vietnam, however, there has been a rapid increase in the number of visitors from America and Europe to Vietnam in recent years. The diversity of foreign tourists is a good signal for the growth of the tourism industry in Vietnam in the future. The efforts to develop tourism of Vietnam are recognized, for example, the Air-Transport-Infrastructure indicator is ranked as the most improved country (WEF, 2019). The tourism in this country proves the attraction from tourism resources, infrastructure and service facilities for various demands of tourists. However, the statistics show that most of the foreign tourists come to Vietnam from the Asia-Pacific region, therefore, it is necessary to implement some specific promotion activities in order to create appropriate tourism products into potential guests and expand the source of visitors from other regions.

\section{The revenue from the tourism sector}

Tourism revenue has been increasing fast for previous years. In the year 2019, Vietnam welcomed 18 million international visitors (raise $16 \%$ compared to 2018), serving 85 million domestic visitors (raise over 6\% compared to the previous year). Related to the number of tourists, the tourism revenue has reached a new record when estimated at over VND 726 trillion (as nearly USD 31.5 billion), accounting for nearly $11.5 \%$ of the national GDP. According to the statistics of GSO, in 2000, the Vietnamese tourism revenue was only VND 17 trillion (approximately USD 0.8 billion), it increased to VND 68 trillion (approximately USD 2.95 billion) in 2009 and then reached VND 726 trillion (approximately USD 31.5 billion) in 2019. During the period of 2000-2019 (20 years), the tourism revenue of Vietnam was 42.5 times higher as compared to the 2000 level (Figure 2).

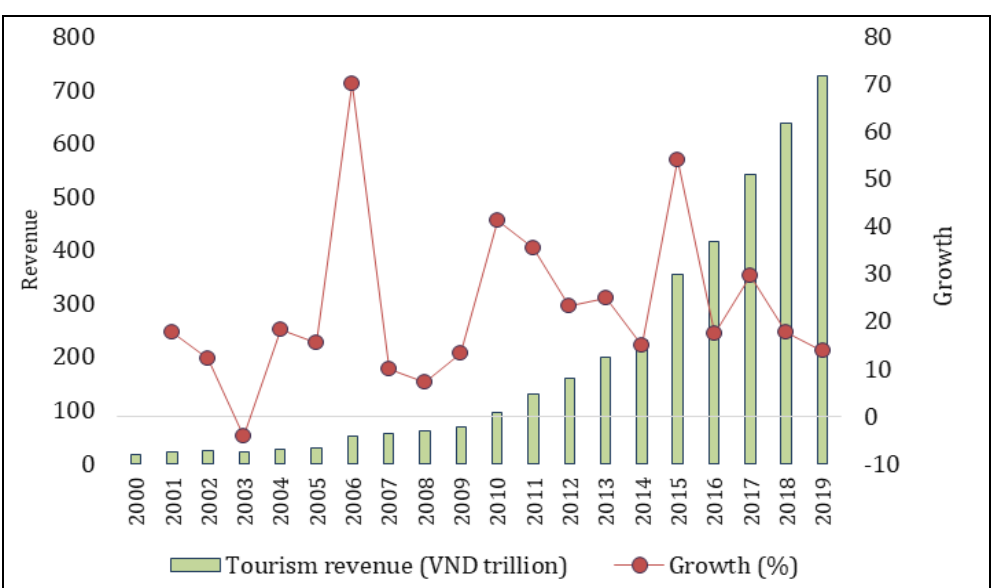

Figure 2. The tourism revenue of Vietnam, 2000-2019

(Source: General Statistics Office of Vietnam, 2019)

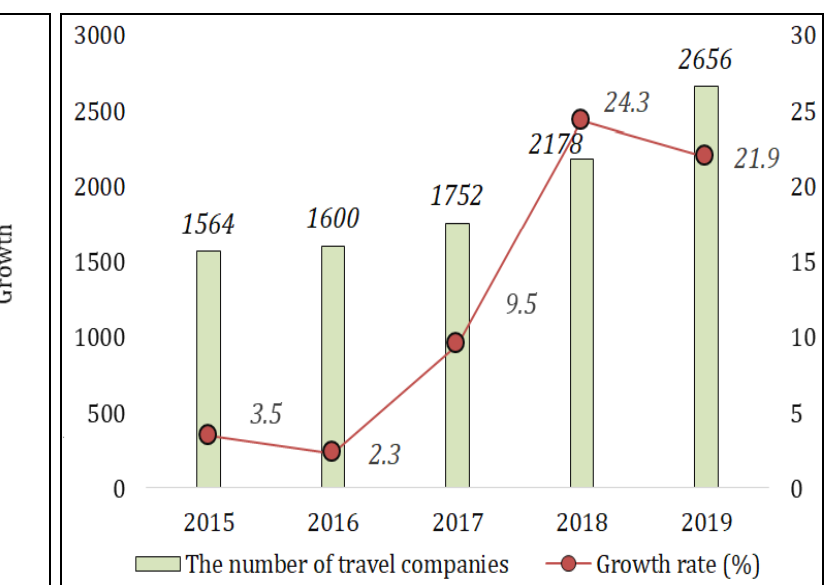

Figure 3. The number of tourism companies in Vietnam, 20152019 (Source: Vietnam National Administration of Tourism, 2020)

The average tourism growth rate of 10 consecutive years of the tourism industry has reached $22.4 \%$ per year in the ten nearest years (2010-2019). The tourism management agencies also predict that the tourism industry will welcome about 20.5 million international visitors and the total revenue from tourism activities will reach over VND 830 thousand billion by 2020. Because of the rapid rise in international visitors, the tourism sector is bringing a significant net inflow of foreign income into the economy. The touri sm sector gradually socializes and diverse forms of investment both domestic and foreign investors. Tourism companies are focused on both the number of tourists and the quality of services. The tourism revenue of Vietnam also will be predicted to grow fast in the next years (Tung, 2018). Because, according to the statistics of VNAT in 2018, a foreign visitor spent USD 900 on average on a trip to Vietnam, this spending level was lower when compared to the spending value at USD 1105 in Singapore, USD 1109 in Indonesia, and USD1565 
Thailand, respectively. Besides, the multiplier effect of tourism spending on the total economy is lower in Vietnam compared to other countries in Southeast Asia (World Bank, 2019). Vietnam has invested more and more in the infrastructure linking between the destinations, this solution can help the tourism industry have a rapid growth in its revenue in the near future. Furthermore, there are some solutions helping to increase the diversity and attractiveness of tourism products and services, which meet the entertainment and shopping needs of visitors. Besides, the number of domestic companies has risen fast in the tourism industry (especially in 2018-2019), there are 2656 travel businesses operating and developing tourism products and ensuring revenue of this service sector. However, the number of tourism companies in Vietnam is still much smaller than in other countries in Southeast-Asia.

\section{The development of the tourism business system}

Due to the robust demand of both domestic and foreign tourists, the number of accommodations has significantly grown in recent years. In detail, by the end of 2018, the country had about 15.6 thousand accommodation establishments with 353.2 thousand st andard rooms (an increase of $56.7 \%$ of the number of establishments and 61.6\% of the number of standard rooms compared to 2013). Besides, many large-scale accommodation facilities with high standards have been put into operation throughout the country.

There are 965 hotels ranked in three stars and above class with more than 126.7 thousand rooms (an increase of $62.1 \%$ in facilities and $97.1 \%$ in a number of rooms compared to 2013). In 2018, the total number of hotel rooms is around 41 times that of 1990, reflecting huge investments channeled into tourism infrastructure in Vietnam (Tuan et al., 2018). The efforts to improve technical ability promote the hotel system to expand business space and time, develop markets, reduce operating costs and help to facilitate tour, route and destination development, linking businesses and developing new tourism products, improving the service quality of the tourism industry in Vietnam. However, many hotels in Vietnam are ranked on the low standard levels and most of these hotels in domestic private ownership (Tuan et al., 2018). The poor status of tourism service infrastructure can be seen in the below figure when this indicator is quite low in the competitiveness matrix of the Vietnam tourism sector (Figure 3).

The tourism sector also provides a huge number of employments for the Vietnamese economy. In detail, in 2018, the employees of Vietnam's tourism industry are calculated as about 2752.6 thousand people, accounting for about $5.1 \%$ of the national labour force. The number of employees in 2018 is higher 3.3 times than the number of employees in 2005 (at 824.5 thou sand people). Furthermore, there are some million people joining as indirect workers in the tourism sector (GSO, 2019). More than $40 \%$ of employees are trained, whether at schools or on-job-training at businesses (Gregg and Vinh, 2016). In the future, Vietnamese tourism is predicted to have a huge demand for employees and offer a higher income level compared to other service sectors. However, there are a lot of tourism business es that are family-based companies, so their management skills are quite limiting. Besides, the labour productivity in Vietnam's tourism sector is quite lower than other sectors in the economy as well as regional competitors (World Bank, 2019).

Overview, in recent years, the fast development of the tourism industry has really helped to form a "tourism economy" in Vietnam with the spread of momentum quickly, thereby, supporting economic growth, helping to solve employment issues, promote culture exchanges, reduce poverty, ensure social security, preserve and promote cultural values, protect the environment in local communities in Vietnam. However, there are some social failures and challenges that need to be considered in order to help tourism go to a new development strategy in the future.

\section{A SWOT ANALYSIS FOR THE VIETNAMESE TOURISM}

The SWOT analysis matrix is a helpful tool to help evaluate and develop an operating strategy in an existing economic sector. This matrix has four factors including Strengths, Weaknesses, Opportunities, and Threats. In order to analyze Vietnamese tourism, we apply this method to re-identify the resources and capabilities of the tourism industry in Vietnam. Based on the analysis result, policy implications will be provided to support the tourism forwarding to a sustainable development pathway in the future.

\section{Strengths}

- Vietnam has a good geographical position including a long coastline with many beautiful landscapes and beaches, islands and archipelagos (Nguyen and Cheung, 2013; Huong and Lee, 2018; Mai and Smith, 2018; Pham-Do and Pham, 2020). Besides, the climate is in a tropical region. This is a huge strength for Vietnam's tourism industry because the good geography is one of the most attractive reasons that foreign tourists come to Vietnam.

- Has a long history for over 4000 years, with a diversity and abundance in cultural traditions, culinary elite, the religious life of an Eastern nation. Vietnam has 54 ethnic communities, it is diverse and rich with many traditional festivals, culture, and cuisine across the country (Trinh and Ryan, 2015). Each ethnic community has a unique culture and cuisine that contributes to the rich and diverse Vietnamese culture and cuisine as a colorful picture, highlighting the unique identity of each ethnic group and region (Michaud and Turner, 2017).

- This country owns a stable political security background, which is also a favorable factor for tourism development. Besides, along with the image of a high openness, a dynamic and fast-growing economy with the participation of free trade agreements with many countries and regions around the world, Vietnam has proved to be a country with an increasing influence on the world economy. Economic policies are supporting the growth of tourism. This is also an advantage for the tourism industry to continue developing strongly on the basis of economic growth.

- Owned a fast-growing economy, the Vietnamese government invests more and more in infrastructure, planning large-scale resorts and high-class hotel systems. Many projects of transport infrastructure, telecommunications infrastructure and synchronous service infrastructure for tourism have been built and upgraded in recent years. In general, the national infrastructure system can well support the development of the tourism sector. Besides, located in the Asia-Pacific region, Vietnam has benefited from the rapidly growing middle class in this region and relies on a high balance of nature and the cultural resources to generate tourism demand.

- This country has a quite large population and a huge young labour force. Besides, the young dynamic population and the hospitable nature of the people are also strong points for the development of tourism. Besides, fast economic growth leads to an increase in income per capita that can help the Vietnamese people go travel more in the future.

- A huge community of overseas Vietnamese people, it is calculated as 5 million people now residing in many developed countries. The overseas Vietnamese people is a strength of Vietnam's tourism because they have a huge demand to travel their homelands.

\section{Weaknesses}

- The diversity of tourism products is still limited. Tourism businesses have not got enough creative and innovative to exploit the available tourism resources of the country. Lack of a night-time economic strategy that could not provide activity taking place in the evening including 
cuisine, entertainment, culture at night. The poor status of services leads to tourist spending being quite lower compared to other countries in the Southeast Asia region. Besides, the loyalty of foreign tourists has been very low because of a small rate of visitors return in recent years.

- Although the infrastructure system has been invested in, however, it still does not meet tourism development demand. The overcrowding and overload in airports, urban areas, and the lack of highways to connect provinces, have limited the "booming trend" of the Vietnamese tourism sector for recent years. The problem of traffic congestion due to a large number of passengers, the lack of connecting infrastructure also creates challenges that can decrease the competitiveness of Vietnamese tourism.

- Environmental pollution is a problem of the tourism business system and also a highlighted weakness of the Vietnamese tourism industry. Pollution leads to food unsafety and increases the costs to ensure cuisine safety inspections to attract tourists.

- Despite having abundant labour force, however, there is a shortage of professional and high-class human resources. In general, the management skills of businesses have not yet met the competitive requirement and integration trend. Besides, communication skills are one of the most significant weaknesses among Vietnamese employees in the tourism sector. There is still a lack of guides fluent in foreign languages and the current human resource only meets about $70 \%$ of the labour demand.

\section{Opportunities}

- The high openness policy of the economy can help to attract more and more international resources coming to Vietnam. Connected to economic exchange activities and investment relationships, tourism also has the opportunity to have more international capital sources to develop the tourism business system and accommodation infrastructure (Kolosinska et al., 2018).

- Have huge benefits from the fast growth of the Asia-Pacific region. Southeast Asia is receiving more interest from global tourists, it can make a positive and significant impact on the Vietnamese tourism industry. Increase interest in Southeast Asian countries can bring great opportunities to take advantage of this to exploit the available tourism resources in Vietnam.

- The increasing security instability in many important territories and tourism markets worldwide is also a good opportunity for Vietnam to take advantage of the stability of its society to increase international tourists visiting in the near future.

- The development of information technology on the Internet platform in the context of the Industrial revolution 4.0, it has created great opportunities for developing countries (such as Vietnam) to strongly and effectively promote images and tourism services promote tourism development.

\section{Threats}

- The competitive level is raising from other countries in the Asia-Pacific region. Vietnam's tourism industry is still in the beginning development process with low management skills, which has forced the tourism industry to improve its competitiveness in order to catch-up with the development of leading countries in the Asia-Pacific region.

- Destroyed landscapes, deforestation, natural disasters, and epidemics in Vietnam have been complicated over the years. There are many restaurants, hotels, and resorts that elude to invest in waste treatment systems as one of the causes leading to the pollution of the marine and tourism environment. Besides, the rapid urbanization of the provinces also creates great challenges for the development of a Vietnamese tourism industry imbued with an Eastern identity. Finally, climate change has brought many risks for tourism development in some tourism sector in the lowland areas such as the Mekong Delta of Vietnam (Huynh and Piracha, 2019).

- Tourism development can increase income inequality among regions. If the government has not got inclusive economic development policies, tourism growth may be a factor creating instability in society because of the conflict between rich and poor people.

- The instability of the global economy. There was some financial and economic crisis with cycles as ten years per time. In the context of a high level in globalization, Vietnam's tourism will get easily stuck in the international economic crises. Besides, the much depending on a specific region is also a threat to Vietnam's tourism when the vast majority of international visitors to Vietnam originate from Northeast Asia, by $60 \%$ in 2018 (VNAT, 2020).

- The risks for community health. There are some infectious disease outbreaks that have increased significantly in recent decades, and when tourism and travel activities rapidly raise, the global spread of the diseases will be expected to grow fast.

\section{CONCLUSION}

Along with the high openness policy promoting economic integration, the Vietnamese tourism industry has been gradually becoming a key economic sector contributing to economic growth in recent years. The achievements of tourism in Vietnam are outstanding with fast growth in many main aspects. The target in the coming years of Vietnam's tourism industry is quite challenging when continuing to maintain a high growth rate. Our paper maybe is the first study in the context of Vietnam's booming tourism industry. The statistical analysis results have described an inclusively increase in the number of domestic tourists, foreign tourists, and tourism revenue. The statistics also show a breakthrough growth in the tourism industry in Vietnam. Besides, this country is also expected to successfully maintain a high growth rate in the tourism sector in the near future. The collected information is based on a comprehensive assessment and analysis of the previous period that is applied to the SWOT approach for Vietnam's tourism industry. Based on statistical analysis and SWOT results, we have some policy implications for tourism development forward a sustainable pathway.

First, increase marketing and introduce the image of the country, people, culture and landscapes of Vietnam to traditional and potential tourism markets. Thoroughly use websites and international television channels to advertise and take advantage of regional conferences and seminars to introduce and promote Vietnam tourism. Emphasize and promote the landscapes ranked by international organizations in order to make differences for Vietnam tourism compared to others. Build representative tourism offices in potential markets. Promote more extensive advertisement to the overseas Vietnamese communities.

Second, attract foreign investment to develop tourism and focus on well-known tourism investors that have successfully done business worldwide, thereby forming a series of tourist destinations closely connected between Vietnam and other markets. The development of the value chain model. Note to the fast economic growth and the growing income in attracting investment flows to the Vietnamese tourism industry because economic development is always a necessary condition to successfully develop different types of tourism. Thoroughly use foreign capital, foreign management skills, and prestigious brands to increase world-class tourist hotels and resorts in Vietnam. In the future, the hotels and resorts in Vietnam will provide facilities to host world-class events such as Miss Universe or global summits.

Third, encourage domestic private companies to join in the tourism sector. Inheriting and expanding the achievements of the innovation economic policy in Vietnam in promoting private resources in various economic fields. This solution will strongly increase 
the competitiveness of Vietnam's tourism because of the high efficiency of the private sector. Besides, replicating some successful private cases in the tourism area in recent years. In addition, promoting the privatization of state-owned companies operating in tourism to mobilize economic resources from socialization.

Fourth, improve the quality of human resources in tourism businesses thereby increasing the competitiveness of the tourism industry. The quality of tourism human resources is a decisive factor for improving the quality of products and services, contributing to turning tourism to become a key economic sector in Vietnam in the future. Human resources must be systematically developed in both quantity and quality by investing in upgrading facilities of a system of vocational training schools managed by the tourism industry to meet the requirements of high-quality manpower in the future. It is necessary to have training programs for tourism managers in the provinces to keep up with the development trends of the tourism industry worldwide.

Fifth, create comprehensive links among the provinces in Vietnam to develop various types of tourism, diverse and abundant tourist destinations. It is necessary to promote the formation of regional links in tourism development among provinces to maximize the advantages of the provinces in a large region.

Sixth, focus on investment in infrastructure, which harmoniously combines industrial development goals with services. Incorporate infrastructure for industrial development in the overall planning for tourism development. Promote public-private partnerships to develop the infrastructure of the economy in general and the tourism industry in particular.

\section{REFERENCES}

Barker, T., \& Üngör, M. (2019). Vietnam: The next Asian Tiger? North American Journal of Economics and Finance, 47, 96-118. https://doi.org/10. 1016/j.najef.2018.11.010

Bednárová, L., Kiseláková, D., \& Onuferová, E. (2018). Competitiveness analysis of tourism in the European Union and in the Slovakia. GeoJournal of Tourism and Geosites, 23(3), 759-771. https://doi.org/10.30892/gtg.23312-326

Hampton, M.P., Jeyacheya, J., \& Long, P.H. (2018). Can Tourism Promote Inclusive Growth? Supply Chains, Ownership and Employment in Ha Long Bay, Vietnam. The Journal of Development Studies, 54 (2), 359-376. https://doi.org/10.1080/00220388.2017.1296572

Huong, P.M., \& Lee, J-H., (2018). Finding important factors affecting local residents' support for tourism development in Ba Be National Park, Vietnam. Forest Science and Technology, 13(3), 126-132. https://doi.org/10.1080/21580103.2017. 1354337

Huynh, V.D., \& Piracha, A. (2019). An evaluation on climate change adaptation for tourism sector in the Mekong Delta of Vietnam. Asia Pacific Journal of Tourism Research, 24(9), 894-911. https://doi.org/10.1080/10941665.2019.1653338

Jansen-Verbeke, M., \& Go, F., (1995). Tourism development in Vietnam. Tourism Management, 16(4), 315-321. https://doi.org/10.1016/0261-5177(95)97356-U

Kolosinska, M., Petrashchak, O., Kolosinskyi, I., \& Katana, A. (2018). Tourism sector in transition economy on example of Ukraine: Determinants of competitiveness. GeoJournal of Tourism and Geosites, 21(1), 239-252. https://doi.org/10.30892/gtg.21119-284

Mai, T., \& Smith, C., (2018). Scenario-based planning for tourism development using system dynamic modelling: A case study of Cat Ba Island, Vietnam. Tourism Management, 68, 336-354. https://doi.org/10.1016/j.tourman.2018.04.005

Michaud, J., \& Turner, S., (2017). Reaching new heights. State legibility in Sa Pa, a Vietnam hill station. Annals of Tourism Research, 66, 37-48. https://doi.org/10.1016/j.annals.2017.05.014

Nguyen, T.H.H., \& Cheung, C., (2013). The classification of heritage tourists: a case of Hue City, Vietnam. Journal of Heritage Tourism, 9(1), 35-50. https://doi.org/10.1080/1743873X.2013.818677

Pham-Do, K.H., \& Pham, T.T.T. (2020). Tourism in marine protected areas: A view from Nha Trang Bay, Vietnam. Tourism Management Perspectives, 33, 100623. https://doi.org/10.1016/j.tmp.2019.100623

Strydom, A.J., Mangope, D., \& Henama, U.S. (2019). Making community-Based tourism sustainable: Evidence from the free state province, South Africa. GeoJournal of Tourism and Geosites, 24(1), 7-18. https://doi.org/10.30892/gtg.24101-338

Thirumaran, K., Dam, M.X., \& Thirumaran, C.M., (2014), Integrating Souvenirs with Tourism Development: Vietnam's Challenges. Tourism Planning \& Development, 11(1), 57-57. https://doi.org/10.1080/21568316.2013.839471

Trinh, T.T., Ryna, C. (2015). Heritage and cultural tourism: the role of the aesthetic when visiting Mỹ Sơn and Cham Museum, Vietnam. Current Issues in Tourism, 19(6), 564-589. https://doi.org/10.1080/13683500.2015.1054269

Truong, D.V. (2012). Tourism policy development in Vietnam: a pro-poor perspective. Journal of Policy Research in Tourism, Leisure and Events, 5(1), 2845. https://doi.org/10.1080/19407963.2012.760224

Truong, V.D., Hall. C.M, \& Garry. T. (2014). Tourism and Poverty Alleviation: Perceptions and Experiences of Poor People in Sapa, Vietnam. Journal of Sustainable Tourism, 22(7), 1071-1089. https://doi.org/10.1080/09669582.2013.871019

Truong, D.V. (2018). Tourism, poverty alleviation, and the informal economy: the street vendors of Hanoi, Vietnam. Tourism Recreation Research, 43(1), 5267. https://doi.org/10.1080/02508281.2017.1370568

Tuan, L.N., Pearce, D.G., \& Smith, K.A. (2018). Distribution channels and ownership of upmarket hotels in a transition economy. International Journal of Hospitality Management, 68, 50-58. https://doi.org/10.1016/j.ijhm.2017.09.008

Tung, L.T. (2018). Forecasting the Foreign Tourist Arrivals to Vietnam using the Autoregressive Integrated Moving Average Method. Journal of Environmental Management and Tourism, 9(6), 1135-1144. https://doi.org/10.14505//jemt.v9.6(30).01

Tung, L.T. (2019a). Does exchange rate affect the foreign tourist arrivals? Evidence in an emerging tourist market. Management Science Letters, 9(8), 11411152. https://doi.org/10.5267/j.msl.2019.5.001

Tung, L.T. (2019b). Does Foreign Direct Investment Really Support Private Investment in an Emerging Economy? An Empirical Evidence in Vietnam. Montenegrin Journal of Economics, 15(1), https://doi.org/7-20.10.14254/1800-5845/2019.15-1.1

*** International Tourism Highlights - 2019 Edition, (2019). World Tourism Organization (UNWTO). Retrieved from https://www.e-unwto.org/doi/pdf/10. $18111 / 9789284421152$

*** Skills for Trade and Economic diversification (STED) in Vietnam: The case of the Tourism sector in selected provinces, (2016). Gregg, C., \& Vinh, N. Q. International Labour Organization, Geneva, Switzerland. Retrieved from https://www.ilo.org/skills/projects/sted/WCMS_551483/lang--en/index.htm

*** Statistics database, (2019). General Statistics Office of Vietnam (GSO). Retrieved from http://www.gso.gov.vn/-Default_en.aspx?tabid=766

*** The Travel \& Tourism Competitiveness Report 2019, (2019). World Economic Forum (WEF). Retrieved from http://www3.weforum.org/docs/ WEF_TTCR_2019.pdf

*** Tourism statistics, (2020). Vietnam National Administration of Tourism (VNAT). Retrieved from http://www.vietnamtourism.gov.vn/

*** Talking Stock Recent Economic Developments of Vietnam-Special Focus: Vietnam's Tourism Development, (2019). World Bank. Retrieved from http:/ documents1.worldbank.org/curated/en/821801561652657954/pdf/Taking-Stock-Recent-Economic-Developments-of-Vietnam-Special-Focus-VietnamsTourism-Developments-Stepping-Back-from-the-Tipping-Point-Vietnams-Tourism-Trends-Challenges-and-Policy-Priorities.pdf

*** World Tourism Barometer, (2020). World Tourism Organization (UNWTO) (2020). Madrid, Spain. Retrieved from https://www.e-unwto.org/doi/pdf/10. 18111/wtobarometereng. 2020.18.1.1. 